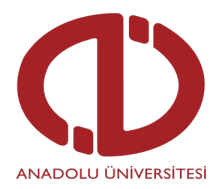

Açıköğretim Uygulamaları ve Araştırmaları Dergisi

AUAd

https://dergipark.org.tr/tr/pub/auad

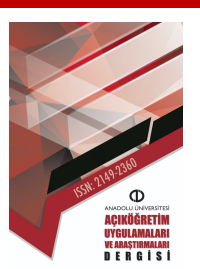

Gönderim: 14.12 .2020

Düzeltme: 16.03 .2021

Kabul: 10.04 .2021

Tür: Araştırma Makalesi

\title{
Öğrenme yönetim sistemi seçiminde kullanılacak kriterlerin belirlenmesine yönelik çok ölçütlü karar verme yöntemi önerisi
}

\author{
Murat ARTSIN ${ }^{\mathrm{a}}$ \\ Kaan GÜNAL ${ }^{b}$
}

a Bilecik Şeyh Edebali Üniversitesi, Açık ve Uzaktan Öğrenme Uygulama ve Araştırma Merkezi, Bilecik. ORCID: 00000002-4975-0238

b Bahçeşehir Üniversitesi, Doktora Öğrencisi, İstanbul. ORCID: 0000-0002-7555-824X

\section{Özet}

Yükseköğretimde Öğrenme Yönetim Sistemleri (ÖYS) her geçen gün önemini artırmaktadır. ÖYS'ler uzaktan eğitim sürecinde öğrencilerin ve öğretim elemanlarının asenkron olarak bir araya geldikleri ortamların oluşmasında faydalanılan alanlardır. Bu çalışmanın amacı yükseköğretimde yer alan üniversitelerin veya uzaktan eğitim kurumlarının ÖYS seçim kriterlerinin oluşturulmasının sağlanmasıdır. Çalışma nitel bir durum çalışması olarak desenlenmiştir. $\mathrm{Bu}$ durum çalışmasında yükseköğretimde görev yapmakta olan uzman profesyoneller ile gerçekleşen görüşmelerin ardından AHP (Analitik Hiyerarşi Süreci) ile süreç organize edilmiştir. Veri toplama bağlamında uzman profesyonellere alanyazın destekli kriter havuzu sunulmuştur. Uzman görüşlerinin beraberinde kriter havuzu nihai halini almıştır. Bu sürecin ardından hazırlanan kriter havuzu farklı bir uzman grubu ile değerlendirilerek kriterlerin kriter ağırlıklarının oluşturulması sağlanmıştır. Çalışmanın sonucunda 6 ana kriterin ve 42 alt kriterin kriter ağırlıkları ortaya çıkmıştır. Ana kriterler ve ağılıklarının sırasıyla; Ölçme ve değerlendirme boyutu $(0,295)$, iletişim boyutu $(0,254)$, içerik boyutu $(0,159)$, topluluk oluşturma boyutu $(0,140)$, teknoloji boyutu $(0,098)$ ve maliyet boyutu $(0,055)$ olduğu tespit edilmiştir. Çalışmadaki alt kriterlerin alanyazındaki diğer birçok çalışma ile desteklenir olması, sunulan bu kriter havuzunun ÖYS seçim kriterleri bağlamında kullanılabilirliğini gözler önüne sermiştir.

Anahtar Sözcükler: Öğrenme yönetim sistemi (ÖYS), Çok kriterli karar verme (ÇKKV), Analitik hiyerarşi süreci (AHS)

\section{Multi-criterion decision making method proposal for determining the criteria for learning management system selection}

\begin{abstract}
Learning Management Systems (LMS) in Higher Education have been increasing their importance every day. LMSs are areas that are used in the remote education process to create environments where students and faculty meet as asynchronously. The aim of this study is to provide the construction of LMS selection criteria of universities or distance education institutions in higher education. The study has been shaped as a qualitative case study. Following interviews with specialist professionals working in higher education in this case study, the process was organized with AHP (Analytical Hierarchy Process). In the context of data collection, literature supported list of criteria has been presented to experts in the field. Along with expert opinions, the list of criteria has taken its final form. After this process, the list of criteria prepared was evaluated with a different group of experts and the weights of criteria have been established. As a result of the study, the weights of 6 main criteria and 42 sub-criteria have been revealed. The main criteria and their weights which are respectively in terms of measurement and evaluation (0.295), communication $(0.254)$, content $(0.159)$, community building $(0.140)$, technology $(0.098)$ and cost $(0.055)$ were detected. The fact that the sub-criteria in the study were supported by many other studies in the field enabled the usability of this list of criteria in the context of the LMS selection criteria.
\end{abstract}

Keywords: Learning Management System (LMS), Multi-Criterion Decision Making (MCDM), Analytical Hierarchy Process (AHP)

Artsın, M. ve Günal, K. (2021). Öğrenme yönetim sistemi seçiminde kullanılacak kriterlerin belirlenmesine yönelik çok ölçütlü karar verme yöntemi önerisi. Açıkögretim Uygulamalarl ve Araştırmaları Dergisi (AUAd), 7(2), 87-108. https://doi.org/10.51948/auad.840404 


\section{Giriş}

Endüstri çağından bu yana takip eden eğitim uygulamalarının kitlesel ve devrimsel uygulamalarından biri olarak uzaktan eğitim, milyonlarca öğrencinin bir araya geldiği eğitim kurumlarının oluşmasını sağlamıştır. Bu devrimsel eğitim yaklaşım, Anadolu Üniversitesi, The Open University ve Indira Gandhi National Open University gibi birçok uzaktan eğitim kurumunun oluşmasına neden olmuştur. Bu köklü kuruluşlar zaman içerisinde sahip oldukları öğrenci sayıları ile mega üniversitelerden (Daniel, 1996) giga üniversitelere (Bozkurt, 2019) dönüşmüşlerdir. Öğrenci sayılarının artmasıyla beraberinde kullanılan teknolojilerde de değişimler gerçekleşmiştir. Bu kullanılan teknolojiler, uzaktan eğitim yoluyla eğitim ortamları sunan bu kurumlardaki öğrencilerin öğrenmesi süreçlerinde zamansal ve mekânsal esneklik sağlamak amacıyla kullanılmaktadır.

Uzaktan eğitim sunan üniversiteler ve programlar, öğrenciler ile etkileşim sağlayabilmek için birçok farklı teknolojiden faydalanmaktadır. Bu teknolojilerden birisi de öğrencilerle ders malzemelerinin paylaşılabileceği ve öğrencilerinin öğrenme-öğretme süreçlerine dair bilgi edinebilecekleri Öğrenme Yönetim Sistemleridir (ÖYS). ÖYS'ler uzaktan eğitim ortamlarında öğrenciler ile iletişimin sağlanabildiği, ders içeriklerinin paylaşılabileceği ve öğrencilerinin davranışlarının izlenebildiği yazılımlardır. ÖYS'ler tasarımsal olarak birbirlerinden farklılıklara sahip olsalar bile, öğrencilerin iyi öğrenme deneyimlerine sahip olabilmeleri gibi ortak bir amaca sahiptirler. ÖYS'ler öğrencilerin kullandıkları yazılımsal bir ortam olduğundan dolayı sistemli çalışabilmesi, tutarlı, hızlı olması, içerik geliştirme araçlarına sahip olmaları gerekmektedir. (Altıparmak, Kurt ve Kapıdere, 2011).

Gelişen yazılımsal teknolojiler sayesinde birçok farklı ÖYS'nin üretildiği günümüzde, birçok farklı lisanslama seçeneklerine sahip ÖYS bulunmaktadır. Yaygın olarak alanda kullanılan ÖYS'ler şunlardır: Moodle, Blackboard, Canvas ve Sakai'dir. Moodle Genel Kamu Lisansı ile lisanslanmış, Php desteği bulunan Linux sunucularda çalışan ve gönüllüler tarafından desteklenen bir ÖYS'dir (Brandl, 2005). Bunun yanı sıra ticari amaçla geliştirilmiş, ücretli olan ÖYS'ler de bulunmaktadır. Blackboard, yaygın olarak kullanılan (Liaw, 2008; Chang, 2014) ve birçok etkileşimin sağlandığ 1 (Tawalbeh, 2018) ticari bir ÖYS'dir. Öte yandan Canvas, Amerika Birleşik Devletleri merkezli eğitim kurumlarında Blackboard'un ardından en çok kullanılan ÖYS'dir (Edutechnica, 2020). Canvas da Moodle gibi açık kaynak kodlu bir ÖYS'dir. Canvas birçok farklı yönetim (Canvas Guides, 2020) ve etkileşim seçeneklerine sahiptir (Pendergast, 2015). Sakai ise birçok kurum ve akademisyen tarafından geliştirilen ve içerisinde sanal sınıf teknolojilerine sahip, açık kaynak kodlu bir ÖYS'dir. 
Uzaktan eğitim endüstrisinde ÖYS'ler büyük bir pazara sahiptir. ÖYS pazarında en çok tercih edilen ÖYS'ler Blackboard ve Canvas'dır (Edutechnica, 2020). Bu platformların öğrencilerin ve kurumların ihtiyaçları doğrultusunda sahip oldukları ortak özellikleri bulunsa da birbirlerinden farklı özelliklere de bulunmaktadır. Uzaktan eğitim imkanı sunan üniversitelerin ÖYS pazarında kendi ihtiyaçlarına uygun yazılımı seçebilmeleri, öğrenmeöğretme sürecinin verimliliği için oldukça önemlidir. Öte yandan alanyazında ÖYS'lerin sahip olmaları gereken kriterlerin uzmanlar tarafından değerlendirildiği çalışmaların bulunmadığı gözlenmektedir. Bu bağlamda bu çalışmada uzaktan eğitim kuramları ve alan uzmanlarının görüşleri çerçevesinde ÖYS seçim kriterleri, alan uzmanları tarafından değerlendirilerek kurumların tüm ihtiyaçlarına yanıt verecek ÖYS'yi belirleyebilmeleri noktasında faydalanabilecekleri kriterlerin ortaya çıkartılması amaçlanmıştır. Bu bağlamda ÖYS kriterlerinin belirlenmesinde Çok Kriterli Karar Verme (ÇKKV) yöntemlerinden faydalanilacaktır.

\section{Çok Kriterli Karar Verme (ÇKKV)}

Çok Kriterli Karar Verme (ÇKKV), farklı yaklaşımları bünyesinde barındıran yöntemler bütünü olup karar biliminin bir alt dalını oluşturmaktadır. ÇKKV, belirlenen kriterlere göre karar sürecinin modellenmesi ve karar vericinin süreç sonunda elde edeceği faydayı azami seviyeye yükseltecek şekilde analiz etmesi sürecine verilen addır. (Hwang ve Yoon, 1981; Chen ve Hwang, 1992; Belton, 1986).

Çok Kriterli Karar Verme (ÇKKV) yöntemleri, 1960'lı yıllarda karar verme işlemlerine yardımcı olacak bir takım yöntemlere ihtiyaç duyulmasıyla birlikte geliştirilmeye başlanmıştır. Karar verme sürecinde alternatifler arasından bir seçimde bulunurken birçok kriterin (faktörün) göz önünde bulundurulması esastır. ÇKKV yöntemlerinin amacı, çok fazla seçenek ve faktörün bulunduğu hallerde karar verme mekanizmasını kontrol altında tutabilmek ve karar sonucunu mümkün olduğu kadar kolay ve çabuk elde etmektir. (Zeleny, 1982; Saaty, 1989)

ÇKKV yöntemleri kariyer planlaması, aile bütçesi planlaması gibi mikro veya üretim planlaması, yatırım kararları gibi makro ölçekte olması fark etmeksizin en iyi performansa sahip alternatifin seçimine veya ulaşılmak istenen amaç doğrultusunda performans sonuçlarına göre en iyiden en kötüye doğru sıralama gerektiren tüm alanlarda kullanılabilmektedir. Örnek olarak finans, muhasebe, pazarlama, planlama, üretim, eğitim, sağlık, ulaştırma, portföy ve pazar seçimi, kamu sektörü, risk analizleri verilebilir. (French, 1988; Russell, 1990; Schuyler, 1996; Von Winterfeldt ve Edwards, 1986). Eğitim alanında da ÇKKV yöntemlerine başvurulmaktadır. Üniversitelerin eğitim kalitesinin değerlendirilmesi (Yacan, 2016), fakülte 
performanslarının analiz edilmesi, eğitim idarecilerinin performansları ve yeterliliklerinin analiz edilmesi ve benzeri konularda ÇKVV uygulamaları gerçekleştirilebilmektedir.

ÇKKV problemlerinde karar vericiler alanlarında uzman olan, kriter, karar değişkeni ve alternatifleri belirleyen kişilerdir. ÇKKV; birden çok kriteri değerlendirerek karar vermeyi amaçlamaktadır. Özetle ÇKKV; belirlenen kriterleri göz önüne alarak en iyi seçimin yapılmasına imkan sağlayan bir araçtır. Karar verme tanımı içerisinde tercih edilen seçim, sınırlamalar ve tercihlerle kısıtlandırılmıştır. Burada belirtilen sınırlamalar, hedeflenen durumların başarılı bir şekilde gerçekleştirilmesi ve tercihidir.

ÇKKV aşağıdaki aşamalardan oluşmaktadır (Vassilev, Genova ve Vassileva, 2005):

- Amaçların belirlenmesi

- Kriterlerin belirlenmesi

- Alternatiflerin belirlenmesi

- Alternatiflerin Kriterlere Uygunluğunun Değerlendirilmesi

- Genel Değerlendirme ve Karar Verme

- Kararın İncelenmesi ve Geri Dönüm

\section{AHP}

AHP, ÇKKV yöntemlerinden birisidir. $\mathrm{Bu}$ yöntem kullanılarak karar verilmesi planlanan problemin çözümü 4 aşamada gerçekleştirilmektedir (Saaty, 1977).

a (Ayrıştırma) Hiyerarşik yapının belirlenmesi.

b İkili karşılaştırma matrisinin oluşturulması.

c (Sentezleme) Öncelik değerlendirmesinin yapılarak puanların hesaplanması.

d (CR) Tutarlılık değeri hesaplanması ve hesaplanan değerlere göre öncelik değerlerinin belirlenmesi.

$\mathrm{Bu}$ yönteme ait aşamaların detayları ise aşağıdaki gibi açıklanabilir.

- Karar verilmesi istenen problemin anlaşılır ve uygulama kolaylığı açısından hiyerarşik bir modele dönüştürülmesi gerekir. Bu sebeple, problemin amacı, kriterleri, alt kriterleri ve alternatifleri hiyerarşik yapı içerisinde şekillendirmektir. Amacı ise kriterlerin öncelik değerlerini belirlemektir. Karşılaştırmalar yapılırken uzman kişiler tarafından genellikle aşağıdaki belirtilen tercih ölçeği kullanılmaktadır (Saaty, 1977). 


\begin{tabular}{|c|c|}
\hline $\begin{array}{l}\text { Tablo 1 } \\
\text { Tercih ölçĕgi }\end{array}$ & Tanımı \\
\hline Önem Derecesi & Eşit derecede önemli \\
\hline 3 & Orta derecede önemli \\
\hline 5 & Güçlü derecede önemli \\
\hline 7 & Çok güçlü derecede önemli \\
\hline 9 & Son derece önemli \\
\hline $2,4,6,8$ & Ara değerler \\
\hline
\end{tabular}

- Matrisi normalize hale getirerek ikili karşılaştırma matrisi ile öğelerinin göreli öncelikleri hesaplanmaktadır.

- $\mathrm{Bu}$ aşamada karşılaştırma matrisleri olarak isimlendirilen A matrisi ile $\mathrm{A} \mathrm{x} \mathrm{w}=\lambda$ max $\mathrm{x}$ w eşitliğini sağlayan $\lambda$ max öz vektörü elde edilmektedir. A uzman kişiler tarafindan oluşturulan karşılaştırma matrisini belirtirken w ise kriter ağırlıklarının matrisini ifade etmektedir. (1.1) ve (1.2)'deki eşitlikler yardımıyla tutarlılık oranı (CR) hesaplanır. CI tutarlılık indeksini ve RI'da rassallık göstergesini ifade etmektedir. Rassallık göstergesi matrisin alternatif miktarına göre farklı değerler alan sabit RI değerlerinden oluşmaktadır.

$$
\begin{aligned}
C I & =\left(\lambda_{\max }-n\right) /(n-1) \\
C R & =C I / R I
\end{aligned}
$$

\begin{tabular}{|c|c|c|c|c|c|c|c|c|c|c|c|c|c|c|c|}
\hline \begin{tabular}{|l} 
Tablo 2 \\
Rassallık
\end{tabular} & & & & & & & & & & & & & & & \\
\hline & 1 & 2 & 3 & 4 & 5 & 6 & 7 & 8 & 9 & 10 & 11 & 12 & 13 & 14 & 15 \\
\hline $\begin{array}{l}\text { Rassallık } \\
\text { Göstergesi }\end{array}$ & 0 & 0 & 0,58 & 0,9 & 1,12 & 1,24 & 1,32 & 1,41 & 1,45 & 1,49 & 1,51 & 1,48 & 1,56 & 1,57 & 1,59 \\
\hline
\end{tabular}


AHP'de $C R<0,1$ ifadesinin olması karşılaştırma matrisinin tutarlı olduğunu gösterir.

- Bu aşamada her bir kriterin ağırlık değeri ile alternatiflerin kriterlere göre önemlerinin çarpımlarının toplamı her bir alternatifin ayrı ayrı öncelik değerini verecektir.

\section{Yöntem}

$\mathrm{Bu}$ çalışma nitel araştırma desenlerinden biri olan durum çalışması olarak tasarlanmıştır. Durum çalışmaları sistemlerin veya olayların incelendiği çalışmalardır (Creswell, 2007). Durum çalışmalarının temel amacı belirli amaçlar çerçevesinde belirli zaman aralığında dokümanlar ve raporlar ile verilerin toplanması beraberinde de temaların ortaya çıkarıldığı çalışmalardır (Creswell, 2013). Birçok farklı disiplinde gerçekleştirilen durum çalışmaları bulunmasına rağmen, Leymun, Odabaşı ve Kabakçı Yurdakul'a (2017) göre eğitim bilimleri alanında gerçekleştirilen durum çalışmalarının kuramlardaki bilgilerin uygulanmasına yönelik iyi verilerin elde edilmesinde faydalı olabileceği ifade edilmektedir. Alanyazın incelendiğinde durum çalışmalarına farklı açılardan da yaklaşıldığı görülmektedir. Unsurların ve etkileşimlerin resmedilmesi amacıyla (Merriam, 2013), olgu ve bağlamlar arasındaki sınırların tam olarak belli olmadığı durumların sunulması (Yin, 2014), karmaşık olguları anlamak amacıyla (Stake, 1995) gerçekleştirilen çalışmalar durum çalışmalarının temelini oluşturmaktadır. Alanyazında durum çalışmalarının belirttiği unsurlardan yola çıkılarak bu çalışmada uzaktan eğitim kuramları temel alınarak uzaktan eğitim hizmeti sunan kurumların öğrenme yönetim sistemi seçim kriterlerinin belirlenmesi amaçlanmıştır. $\mathrm{Bu}$ çalışmanın ana araştırma sorusu; uzaktan eğitim hizmetleri sunan kurumların öğrenme yönetim sistemi seçerken dikkat etmeleri gereken kriterler nelerdir?

\section{Araştırmanın Aşamaları}

Bu çalışma kapsamında Türkiye'de aktif olarak görev yapmakta olan açık ve uzaktan eğitim ve eğitim teknolojisi alanında üniversitelerin akademik ve idari birimlerinde görev alan öğretim elemanı $(n=4)$ ve idari personellerine $(n=1)$ ulaşılmıştır. Çalışmaya katılan katılımcıların en az 5 yıllık uzaktan eğitim deneyimi bulunmaktadır.

Çalışmanın ilk aşamasında yazarlar tarafından uzaktan eğitim kuramları temel alınarak bir kriter havuzu oluşturulmuştur. Oluşturulan her kriter alan yazındaki bulgular ile desteklenmiştir. Bunun ardından ilk uzman görüşlerinin alınması için uzmanlara iletilmiştir. Uzmanlar açık ve uzaktan eğitim ve eğitim teknolojisi alanında üniversitelerin akademik ve idari birimlerinde görev alan öğretim elemanı $(n=4)$ ve idari personellerdir $(n=1)$. Uzmanlara 
sunulan alan yazın destekli kriterler, uzmanlar tarafından değerlendirilerek çalışmada yararlanılacak olan nihai ana kriterlerin ve alt kriterlerin oluşturulması gerçekleştirilmiştir. Uzmanlar bu aşamada yeni kriterlerin eklenmesini, bazı kriterlerin güncellenmesini ve bazı kriterlerin de çıkartılmasını önermiştirler. İkinci aşamada ise uzmanların geri bildirimleri neticesinde oluşturulan nihai ana kriterler ve alt kriterler, çalışmada tanımlanmış olan uzman karar verici pozisyonundaki bir gruba $(n=5)$ iletilmiş ve bu sayede AHP süreci için gerekli olan verinin elde edilmesi sağlanmıştır.

Oluşturulan kriterlerin öncelikle alanyazın desteği ile oluşturulması çalışmanın güvenilirliğini sağlamıştır. İlk aşamada açık ve uzaktan eğitim ve eğitim teknolojisi alanındaki üniversitelerin akademik ve idari birimlerinde görev alan öğretim elemanlarının ve idari personellerinin uzman görüşlerinin alınmasında amaçlı örneklemden faydalanılması çalışmanın diş geçerliliği bağlamında değerlendirilmiştir. Bu çalışmanın inandırıcılığ amacıyla uzman grubun katılımcı teyidi sağlanarak iç geçerlilik sağlanmıştır. İç geçerlilik amacıyla uzmanlara elektronik posta ve telefon üzerinden ulaşılmıştır. Kriterler için görüşleri alınmış ve düzenlemeler sonrasında da onayları alınmıştır. Uzman görüşlerinin elde edilmesi, uzman katılımcılarının teyidi ve uzman incelemeleri sağlanarak çalışmanın inandırıcılığg temellendirilmiştir. Uzmanların eklemek veya çıkarmak istedikleri kriterlerin belirlenmesi için her uzmanla birden fazla görüşme gerçekleştirilmiştir. İlk görüşmelerin sonucunda ana kriter havuzu ve alt kriter havuzu elde edilmiş ve ikinci aşamada ise oluşturulan kriterlerin değerlendirilmesi sağlanarak söz konusu ÖYS belirleme yönteminin oluşturulması gerçekleştirilmiştir. Kriter ağırlıkları AHP ile analiz edilmiş olup kriterlerin kendi içlerindeki CR değeri 0,10’un altında olduğu tespit edildiği için tutarlı oldukları sonucuna varılmıştır.

\section{Bulgular}

$\mathrm{Bu}$ çalışmada alan yazın desteğiyle oluşturulan ÖYS belirleme kriterleri, uzmanlar tarafından değerlendirilerek söz konusu kriterlerin belirlenmesi gerçekleştirilmiştir. Uzmanlar ile gerçekleştirilen birden çok görüşmeyle kriter havuzunun oluşturulması sağlanmıştır. $\mathrm{Bu}$ uygulamanın amacı, kurumların ÖYS seçim süreçlerinde kullanacakları kriterlerin uzmanlar tarafından ağırlıklandırılmasıdır. Bu analizin sonucunda elde edilen ağırlıklandırma ile ÖYS kriterleri sunulmuştur. 


\section{AHP Yöntemi ile Ana Kriter Ağırlıklarının Belirlenmesi}

Çalışma kapsamında belirlenen ana kriterlerin ağırlıklarının hesaplanabilmesi için uzmanlara iletilen veri toplama aracı üzerinden elde edilen verilerle gerçekleştirilen matematiksel işlemler aşağıdaki gibidir;

\begin{tabular}{|c|c|c|c|c|c|c|}
\hline $\begin{array}{l}\text { Tablo } 3 \\
\text { Ana krite } \\
\text { matrisi }\end{array}$ & in $u z h$ & dele & eome & rtala & na a & \\
\hline $\mathbf{K}$ & K1 & K2 & $\mathbf{K 3}$ & K4 & K5 & K6 \\
\hline K1 & 1,000 & 0,574 & 1,191 & 2,268 & 0,425 & 2,652 \\
\hline K2 & 1,741 & 1,000 & 2,268 & 2,268 & 0,725 & 4,690 \\
\hline K3 & 0,839 & 0,441 & 1,000 & 1,600 & 0,582 & 2,426 \\
\hline K4 & 0,441 & 0,441 & 0,625 & 1,000 & 0,349 & 2,169 \\
\hline K5 & 2,352 & 1,380 & 1,719 & 2,862 & 1,000 & 4,644 \\
\hline K6 & 0,377 & 0,213 & 0,412 & 0,461 & 0,215 & 1,000 \\
\hline
\end{tabular}

Tablo 4

Tutarlılık göstergeleri ve tutarlılık oranları

\begin{tabular}{l|l} 
Ana Kriter & $\mathrm{CI}=(6,0671-6) /(6-1)=0,0134$
\end{tabular}
$\mathrm{CR}=0,0134 / 1,24=0,0108$

\begin{tabular}{|c|c|c|}
\hline $\begin{array}{l}\text { Tablo } 5 \\
\text { Ana kriterlerin ă̆ırlıklarını }\end{array}$ & & \\
\hline Ana Kriter & $\mathbf{W}$ & Siralama \\
\hline Ölçme ve Değerlendirme Boyutu & 0,295 & 1 \\
\hline İletişim Boyutu & 0,254 & 2 \\
\hline İçerik Boyutu & 0,159 & 3 \\
\hline Topluluk Oluşturma & 0,140 & 4 \\
\hline Teknoloji Boyutu & 0,098 & 5 \\
\hline Maliyet Boyutu & 0,055 & 9 \\
\hline
\end{tabular}


Tablo 5'de ve Tablo 6'da belirtilen kriterlerin ağırlıklandırılması için Saaty (1977) tarafından geliştirilmiş olan ve AHP analizlerinde kullanılan '1-9 ölçeği' kullanılmıştır. Söz konusu bu ölçek, AHP analizlerinde yaygın olarak kullanılmakta ve alanda kabul görmüş bir ölçektir. Gerçekleştirilen AHP ağırlıklarının hesaplanmasının ardından uzmanların ÖYS seçimi sırasında Ölçme ve Değerlendirme Boyutuna (0,295) verdikleri ağırlığın diğer kriterlere göre daha yüksek olarak ortaya çıkmıştır. Ölçme ve Değerlendirme Boyutunun ardından İletişim Boyutu $(0,254)$, İçerik Boyutu $(0,159)$, Topluluk Oluşturma $(0,140)$, Teknoloji Boyutu $(0,098)$ ve Maliyet Boyutu'nun $(0,055)$ yer aldığı görülmektedir.

\section{AHP Yöntemi ile Alt Kriter Ăğılıklarının Belirlenmesi}

Çalışma kapsamında uzman görüşleri sonucunda belirlenen alt kriterler Tablo 6'da yer almaktadir.

Tablo 6

ÖYS'lere ait belirlenen alt kriterler

\begin{tabular}{|c|c|}
\hline Ana kriter & Alt Kriter \\
\hline \multirow[t]{7}{*}{ K1: İçerik Boyutu } & K11: Microsoft (Word, Excel, Powerpoint) ürünlerinin derslerin içerisinde kullanımının sağlanabilmesi \\
\hline & $\begin{array}{l}\text { K12: Google Drive (Word, Excel, Powerpoint, Anketler) ürünlerinin derslerin içerisinde kullanımının } \\
\text { sağlanabilmesi }\end{array}$ \\
\hline & K13: Diğer bulut depolama ortamlarındaki ders malzemelerinin derslerin içerisindeki kullanımının sağlanabilmesi \\
\hline & K14: Etkileşimli video malzemelerinin oluşturulması ve düzenlenmesinin sağlanabilmesi \\
\hline & $\begin{array}{l}\text { K15: Evrensel formattaki (pdf, txt, } \mathrm{mp} 3, \mathrm{mp} 4 \text {, png, jpg, swf ) malzemelerinin derslerde kullanımının } \\
\text { sağlanabilmesi }\end{array}$ \\
\hline & K16: Youtube vb. video paylaşım ortamlarındaki videoların derslerde kullanımının sağlanabilmesi \\
\hline & K17: Etkileşimli e-kitapların derslerin içerisinde kullanımının sağlanabilmesi \\
\hline \multirow{7}{*}{$\begin{array}{l}\text { K2: } \\
\text { Boyutu }\end{array}$} & K21: Birebir mesajlaşma seçeneklerinin sağlanabilmesi \\
\hline & K22: Bire çok mesajlaşma seçeneklerinin sağlanabilmesi \\
\hline & K23: Öğrenci-öğrenci mesajlaşma seçeneklerinin sağlanabilmesi \\
\hline & K24: Mobil uygulama içerisinde anında bildirim seçeneklerinin sağlanabilmesi \\
\hline & K25: SMS bildirim seçeneklerinin sağlanabilmesi \\
\hline & K26: Mail bildirim seçeneklerinin sağlanabilmesi \\
\hline & K27: Tartışma formunun etkili kullanımının sağlanabilmesi \\
\hline
\end{tabular}




\begin{tabular}{|c|c|}
\hline & K28: Öğrenenlere çeşitli bildirim seçenekleri sağlanabilmesi \\
\hline \multirow{8}{*}{$\begin{array}{l}\text { K3: Topluluk } \\
\text { Oluşturma }\end{array}$} & K31: Microsoft Teams Meetings'in dersler içerisinde kullanımının sağlanabilmesi \\
\hline & K32: Google hangouts'ın dersler içerisinde kullanımının sağlanabilmesi \\
\hline & K33: Blog araçlarının derslerin içerisinde kullanımının sağlanabilmesi \\
\hline & K34: Wiki araçlarının derslerin içerisinde kullanımının sağlanabilmesi \\
\hline & K35: Grup çalışmalarının derslerin içerisinde kullanımının sağlanabilmesi \\
\hline & K36: Ders günlüklerinin oluşturulmasının sağlanabilmesi \\
\hline & K37: Dersler içerisinde grup yönetim seçeneklerinin kullanımının sağlanabilmesi \\
\hline & K38: Sosyal medya araçlarının entegre kullanılabilmesine olanak sağlama \\
\hline \multirow{5}{*}{$\begin{array}{l}\text { K4: } \\
\text { Boyutu }\end{array}$} & K41: SCORM paketlerinin entegre edilmesi ve derslerde kullanımının sağlanabilmesi \\
\hline & K42: LTI standartlarının desteklenmesinin sağlanabilmesi \\
\hline & K43: Farklı cihazlar için duyarlı tasarımların sağlanabilmesi \\
\hline & K44: 3.parti bulut teknolojilerinin derslerin içerisinde kullanımının sağlanabilmesi \\
\hline & K45: Sanal sınıfların oluşturulan derslerde kullanılabilmesi \\
\hline \multirow{9}{*}{$\begin{array}{l}\text { K5: Ölçme ve } \\
\text { Değerlendirme } \\
\text { Boyutu }\end{array}$} & K51: Test ve ödev araçlarının derslerin içerisinde kullanılabilmesi \\
\hline & K52: Derslerin içerisinde soru havuzu oluşturulabilmesi \\
\hline & K53: Portfolyo geliştirme süreçlerinin dersler içerisinde kullanılabilmesi \\
\hline & K54: Akran değerlendirmesine imkan sağlanabilmesi \\
\hline & $\begin{array}{l}\text { K55: Ya/ya da, dosya yanıtı, eşleşme, doğru/yanlış seçeneklerine sahip soru oluşturma seçeneklerinin } \\
\text { sağlanabilmesi }\end{array}$ \\
\hline & $\begin{array}{l}\text { K56: Kısa yanıt, çoktan seçmeli, boşluk doldurma, likert soru seçeneklerine sahip soru oluşturma seçeneklerinin } \\
\text { sağlanabilmesi }\end{array}$ \\
\hline & K55: Sınavlar için Test Modu ile sınav gerçekleştirme seçeneklerinin sağlanabilmesi \\
\hline & K58: ePortfolyo oluşturmaya olanak tanıması \\
\hline & K59: Ödev oluşturma, ödevleri öğrencilere atama, ve rubrik ile sistem üzerinden değerlendirmeye olanak tanıması \\
\hline \multirow{5}{*}{$\begin{array}{l}\text { K6: } \\
\text { Boyutu }\end{array}$} & K61: Y1llık bakım güncelleme maliyeti \\
\hline & K62: Yaz1lım/Lisans maliyeti \\
\hline & K63: Danışmanlık hizmeti maliyeti \\
\hline & K64: Donanım altyapı maliyeti \\
\hline & K65: Genel Yönetim maliyeti \\
\hline
\end{tabular}

Ana kriterler K1, K2, K3, K4, K5 ve K6 olarak listelenmiş, beraberinde ise alt kriterler yer almıştır. Uzman kadrosu birden fazla karar vericiden meydana geldiği için grup karar vermeden faydalanılmıştır. Bu sebeple uzmanların kriterlere verdikleri ağırlıklandırmaların 
hesaplanabilmesi için geometrik ortalamaları alınmıştır. Böylelikle kriterler hakkında farklı uzmanların kriter ağırlıkları bir araya getirilmiştir. Söz konusu bu analiz, ikinci aşamada verilen nihai kriterlerin değerlendirilmesine ait kriter ağırlıklarıyla gerçekleştirilmektedir. $\mathrm{Bu}$ aşamada her uzman eşit düzeyde olacak şekilde bir hesaplama gerçekleştirilmiştir. Gerçekleştirilen matematiksel işlemler aşağıdaki gibidir;

\section{Tablo 7}

Uzman ifadelerinin geometrik ortalamalarına ait karar matrisi

\begin{tabular}{|l|l|l|l|l|l|l|l|}
\hline K1 & K11 & K12 & K13 & K14 & K15 & K16 & K17 \\
\hline K11 & 1,000 & 0,301 & 0,594 & 0,460 & 0,361 & 0,361 & 0,544 \\
\hline K12 & 3,323 & 1,000 & 0,488 & 0,608 & 0,280 & 0,435 & 0,574 \\
\hline K13 & 1,683 & 2,048 & 1,000 & 0,557 & 0,389 & 0,426 & 0,776 \\
\hline K14 & 2,174 & 1,644 & 1,796 & 1,000 & 0,485 & 0,390 & 0,437 \\
\hline K15 & 2,766 & 3,565 & 2,569 & 2,063 & 1,000 & 1,783 & 2,290 \\
\hline K16 & 2,766 & 2,297 & 2,346 & 2,561 & 0,561 & 1,000 & 1,403 \\
\hline K17 & 1,838 & 1,741 & 1,289 & 2,290 & 0,437 & 0,713 & 1,000 \\
\hline
\end{tabular}

\begin{tabular}{|l|l|l|l|l|l|l|l|l|}
\hline K3 & K31 & K32 & $K 33$ & $K 34$ & $K 35$ & $K 36$ & $K 37$ & $K 38$ \\
\hline K31 & 1,000 & 1,031 & 0,828 & 0,763 & 0,665 & 0,665 & 0,704 & 2,237 \\
\hline K32 & 0,970 & 1,000 & 0,922 & 0,862 & 0,792 & 0,839 & 0,714 & 0,894 \\
\hline K33 & 1,208 & 1,084 & 1,000 & 0,435 & 0,415 & 0,699 & 0,392 & 1,027 \\
\hline K34 & 1,310 & 1,160 & 2,297 & 1,000 & 0,877 & 0,822 & 0,322 & 0,970 \\
\hline K35 & 1,505 & 1,262 & 2,408 & 1,140 & 1,000 & 1,516 & 0,561 & 1,741 \\
\hline K36 & 1,505 & 1,191 & 1,431 & 1,217 & 0,660 & 1,000 & 0,500 & 0,871 \\
\hline K37 & 1,421 & 1,401 & 2,551 & 3,104 & 1,783 & 2,000 & 1,000 & 0,922 \\
\hline K38 & 0,447 & 1,118 & 0,974 & 1,031 & 0,574 & 1,149 & 1,084 & 1,000 \\
\hline
\end{tabular}

\begin{tabular}{|l|l|l|l|l|l|l|l|l|l|}
\hline K5 & K51 & $K 52$ & $K 53$ & $K 54$ & $K 55$ & $K 56$ & $K 57$ & $K 58$ & $K 59$ \\
\hline K51 & 1,000 & 1,180 & 0,392 & 0,576 & 1,557 & 0,502 & 0,625 & 0,824 & 0,517 \\
\hline K52 & 0,848 & 1,000 & 0,517 & 0,488 & 0,331 & 0,359 & 0,412 & 0,530 & 0,415 \\
\hline K53 & 2,551 & 1,933 & 1,000 & 0,370 & 0,740 & 0,258 & 0,312 & 0,282 & 0,231 \\
\hline K54 & 1,736 & 2,048 & 2,702 & 1,000 & 0,744 & 0,284 & 0,375 & 0,326 & 0,380 \\
\hline K55 & 0,642 & 3,022 & 1,351 & 1,343 & 1,000 & 0,276 & 0,474 & 0,590 & 0,498 \\
\hline K56 & 1,994 & 2,787 & 3,882 & 3,519 & 3,630 & 1,000 & 1,320 & 0,608 & 0,517 \\
\hline K57 & 1,600 & 2,426 & 3,201 & 2,667 & 2,112 & 0,758 & 1,000 & 1,361 & 0,428 \\
\hline K58 & 1,213 & 1,888 & 3,545 & 3,064 & 1,695 & 1,644 & 0,735 & 1,000 & 0,922 \\
\hline K59 & 1,93 & 2,41 & 4,32 & 2,63 & 2,01 & 1,93 & 2,34 & 1,08 & 1,000 \\
\hline
\end{tabular}

\begin{tabular}{|l|l|l|l|l|l|l|l|l|}
\hline K2 & $K 21$ & $K 22$ & $K 23$ & $K 24$ & $K 25$ & $K 26$ & $K 27$ & $K 28$ \\
\hline$K 21$ & 1,000 & 0,574 & 0,678 & 0,370 & 0,871 & 0,608 & 0,488 & 0,488 \\
\hline$K 22$ & 1,741 & 1,000 & 0,488 & 0,425 & 0,944 & 0,530 & 0,425 & 0,315 \\
\hline$K 23$ & 1,476 & 2,048 & 1,000 & 0,274 & 0,715 & 0,280 & 0,213 & 1,024 \\
\hline$K 24$ & 2,702 & 2,352 & 3,650 & 1,000 & 2,862 & 2,491 & 0,425 & 2,702 \\
\hline K25 & 1,149 & 1,059 & 1,398 & 0,349 & 1,000 & 0,565 & 0,199 & 0,281 \\
\hline$K 26$ & 1,644 & 1,888 & 3,565 & 0,401 & 1,770 & 1,000 & 0,191 & 0,238 \\
\hline$K 27$ & 2,048 & 2,352 & 4,704 & 2,352 & 5,036 & 5,223 & 1,000 & 2,491 \\
\hline K28 & 2,048 & 3,178 & 0,850 & 0,370 & 3,554 & 4,193 & 0,401 & 1,000 \\
\hline
\end{tabular}

\begin{tabular}{|l|l|l|l|l|l|}
\hline K4 & $K 41$ & $K 42$ & $K 43$ & $K 44$ & $K 45$ \\
\hline K41 & 1,000 & 1,046 & 0,660 & 1,046 & 0,590 \\
\hline K42 & 0,956 & 1,000 & 0,594 & 0,660 & 0,389 \\
\hline K43 & 1,516 & 1,683 & 1,000 & 0,871 & 0,530 \\
\hline K44 & 0,956 & 1,516 & 1,149 & 1,000 & 0,362 \\
\hline K45 & 1,695 & 2,569 & 1,888 & 2,759 & 1,000 \\
\hline
\end{tabular}

\begin{tabular}{|l|l|l|l|l|l|}
\hline K6 & K61 & K62 & K63 & K64 & K65 \\
\hline K61 & 1,000 & 0,561 & 0,944 & 0,461 & 0,822 \\
\hline K62 & 1,783 & 1,000 & 1,933 & 1,783 & 2,221 \\
\hline K63 & 1,059 & 0,517 & 1,000 & 0,488 & 1,217 \\
\hline K64 & 2,169 & 0,561 & 2,048 & 1,000 & 2,352 \\
\hline K65 & 1,217 & 0,450 & 0,822 & 0,425 & 1,000 \\
\hline
\end{tabular}




\begin{tabular}{|c|c|}
\hline $\begin{array}{l}\text { Tablo } 8 \\
\text { Tutarlılık göstergeleri }\end{array}$ & \\
\hline \multirow[b]{2}{*}{ K1 } & $\mathrm{CI}=(7,349-7) /(7-1)=0,0582$ \\
\hline & $\mathrm{CR}=0,0582 / 1,32=0,0441$ \\
\hline \multirow[b]{2}{*}{ K2 } & $\mathrm{CI}=(8,828-8) /(8-1)=0,1184$ \\
\hline & $\mathrm{CR}=0,1184 / 1,41=0,0839$ \\
\hline \multirow{2}{*}{ K3 } & $\mathrm{CI}=(8,367-8) /(8-1)=0,0525$ \\
\hline & $\mathrm{CR}=0,0525 / 1,41=0,0372$ \\
\hline \multirow[b]{2}{*}{ K4 } & $\mathrm{CI}=(5,00707-5) /(5-1)=0,0176$ \\
\hline & $\mathrm{CR}=0,0176 / 1,12=0,0158$ \\
\hline \multirow[b]{2}{*}{ K5 } & $\mathrm{CI}=(9,7784-9) /(9-1)=0,0973$ \\
\hline & $\mathrm{CR}=0,0973 / 1,45=0,0671$ \\
\hline \multirow[b]{2}{*}{ K6 } & $\mathrm{CI}=(5,0725-5) /(5-1)=0,0181$ \\
\hline & $\mathrm{CR}=0,0181 / 1,12=0,0162$ \\
\hline
\end{tabular}


Tablo 9

Ana kriterler bağlamında alt kriterlerin sıralaması

\begin{tabular}{|c|c|c|c|}
\hline Ana kriter & Alt Kriter & $\mathbf{W}$ & Siralama \\
\hline \multirow[t]{7}{*}{ K1: İçerik Boyutu } & $\begin{array}{l}\text { K15: Evrensel formattaki (pdf, txt, mp3, mp4, png, jpg, swf) malzemelerinin } \\
\text { derslerde kullanımının sağlanabilmesi }\end{array}$ & 0,270 & 1 \\
\hline & $\begin{array}{l}\text { K16: Youtube vb. video paylaşım ortamlarındaki videoların derslerde } \\
\text { kullanımının sağlanabilmesi }\end{array}$ & 0,202 & 2 \\
\hline & K17: Etkileşimli e-kitapların derslerin içerisinde kullanımının sağlanabilmesi & 0,147 & 3 \\
\hline & $\begin{array}{l}\text { K14: Etkileşimli video malzemelerinin oluşturulması ve düzenlenmesinin } \\
\text { sağlanabilmesi }\end{array}$ & 0,119 & 4 \\
\hline & $\begin{array}{l}\text { K13: Diğer bulut depolama ortamlarındaki ders malzemelerinin derslerin } \\
\text { içerisindeki kullanımının sağlanabilmesi }\end{array}$ & 0,105 & 5 \\
\hline & $\begin{array}{l}\text { K12: Google Drive (Word, Excel, Powerpoint, Anketler) ürünlerinin } \\
\text { derslerin içerisinde kullanımının sağlanabilmesi }\end{array}$ & 0,093 & 6 \\
\hline & $\begin{array}{l}\text { K11: Microsoft (Word, Excel, Powerpoint) ürünlerinin derslerin içerisinde } \\
\text { kullanımının sağlanabilmesi }\end{array}$ & 0,064 & 7 \\
\hline \multirow{8}{*}{$\begin{array}{l}\text { K2: } \\
\text { Boyutu }\end{array}$} & K27: Tartışma formunun etkili kullanımın sağlanabilmesi & 0,283 & 1 \\
\hline & $\begin{array}{l}\text { K24: Mobil uygulama içerisinde anında bildirim seçeneklerinin } \\
\text { sağlanabilmesi }\end{array}$ & 0,193 & 2 \\
\hline & K28: Öğrenenlere çeşitli bildirim seçenekleri sağlanabilmesi & 0,152 & 3 \\
\hline & K26: Mail bildirim seçeneklerinin sağlanabilmesi & 0,100 & 4 \\
\hline & K23: Öğrenci-öğrenci mesajlaşma seçeneklerinin sağlanabilmesi & 0,076 & 5 \\
\hline & K22: Bire çok mesajlaşma seçeneklerinin sağlanabilmesi & 0,070 & 6 \\
\hline & K21: Birebir mesajlaşma seçeneklerinin sağlanabilmesi & 0,065 & 7 \\
\hline & K25: SMS bildirim seçeneklerinin sağlanabilmesi & 0,062 & 8 \\
\hline \multirow{8}{*}{$\begin{array}{l}\text { K3: Topluluk } \\
\text { Oluşturma }\end{array}$} & $\begin{array}{l}\text { K37: Dersler içerisinde grup yönetim seçeneklerinin kullanımının } \\
\text { sağlanabilmesi }\end{array}$ & 0,202 & 1 \\
\hline & K35: Grup çalışmalarının derslerin içerisinde kullanımının sağlanabilmesi & 0,152 & 2 \\
\hline & K34: Wiki araçlarının derslerin içerisinde kullanımının sağlanabilmesi & 0,118 & 3 \\
\hline & K36: Ders günlüklerinin oluşturulmasının sağlanabilmesi & 0,116 & 4 \\
\hline & $\begin{array}{l}\text { K31: Microsoft Teams Meetings'in dersler içerisinde kullanımının } \\
\text { sağlanabilmesi }\end{array}$ & 0,113 & 5 \\
\hline & K38: Sosyal medya araçlarının entegre kullanılabilmesine olanak sağlama & 0,110 & 6 \\
\hline & K32: Google hangouts'ın dersler içerisinde kullanımının sağlanabilmesi & 0,102 & 7 \\
\hline & K33: Blog araçlarının derslerin içerisinde kullanımının sağlanabilmesi & 0,087 & 8 \\
\hline
\end{tabular}




\begin{tabular}{|c|c|c|c|}
\hline K4: $\quad$ Teknoloji & K45: Sanal sınıfların oluşturulan derslerde kullanılabilmesi & 0,349 & 1 \\
\hline Boyutu & K43: Farklı cihazlar için duyarlı tasarımların sağlanabilmesi & 0,195 & 2 \\
\hline & $\begin{array}{l}\text { K44: 3.parti bulut teknolojilerinin derslerin içerisinde kullanımının } \\
\text { sağlanabilmesi }\end{array}$ & 0,170 & 3 \\
\hline & $\begin{array}{l}\text { K41: SCORM paketlerinin entegre edilmesi ve derslerde kullanımının } \\
\text { sağlanabilmesi }\end{array}$ & 0,158 & 4 \\
\hline & K42: LTI standartlarının desteklenmesinin sağlanabilmesi & 0,127 & 5 \\
\hline K5: Ölçme ve & $\begin{array}{l}\text { K59: Ödev oluşturma, ödevleri ögrencilere atama, ve rubrik ile sistem } \\
\text { üzerinden değerlendirmeye olanak tanıması }\end{array}$ & 0,194 & 1 \\
\hline Boyutu & $\begin{array}{l}\text { K56: Kısa yanıt, çoktan seçmeli, boşluk doldurma, likert soru seçeneklerine } \\
\text { sahip soru oluşturma seçeneklerinin sağlanabilmesi }\end{array}$ & 0,165 & 2 \\
\hline & K58: ePortfolyo oluşturmaya olanak tanıması & 0,150 & 3 \\
\hline & $\begin{array}{l}\text { K55: Sinavlar için Test Modu ile sınav gerçekleştirme seçeneklerinin } \\
\text { sağlanabilmesi }\end{array}$ & 0,140 & 4 \\
\hline & $\begin{array}{l}\text { K55: Ya/ya da, dosya yanıtı, eşleşme, doğru/yanlış seçeneklerine sahip soru } \\
\text { oluşturma seçeneklerinin sağlanabilmesi }\end{array}$ & 0,080 & 5 \\
\hline & K54: Akran değerlendirmesine imkan sağlanabilmesi & 0,078 & 6 \\
\hline & K51: Test ve ödev araçlarının derslerin içerisinde kullanılabilmesi & 0,077 & 7 \\
\hline & K53: Portfolyo geliştirme süreçlerinin dersler içerisinde kullanılabilmesi & 0,065 & 8 \\
\hline & K52: Derslerin içerisinde soru havuzu oluşturulabilmesi & 0,052 & 9 \\
\hline Maliyet & K62: Yaz1lım/Lisans maliyeti & 0,315 & 1 \\
\hline Boyutu & K64: Donanım altyapı maliyeti & 0,267 & 2 \\
\hline & K63: Danışmanlık hizmeti maliyeti & 0,148 & 3 \\
\hline & K61: Yıllık bakım güncelleme maliyeti & 0,136 & 4 \\
\hline & K65: Genel Yönetim maliyeti & 0,134 & 5 \\
\hline
\end{tabular}

AHP sonucunda Tablo 9'da yer alan ana kriterlere göre alt kriter siralaması ortaya çıkmıştır. İçerik boyutu kriterinin değerlendirilmesinin sonucunda 0,270 ağırlık ile evrensel formattaki (pdf, txt, mp3, mp4, png, jpg, swf) malzemelerin derslerde kullanımının sağlanabilmesinin en yüksek değere sahip alt kriter olduğu tespit edilmiştir. İletişim boyutu kriterinin değerlendirilmesinin sonucunda 0,283 ağırlık ile tartışma formunun etkili kullanımının sağlanabilmesinin en yüksek değere sahip alt kriter olduğu belirlenmiştir. Topluluk Oluşturma ana kriteri değerlendiğinde ise 0,202 ağırlık ile dersler içerisinde grup yönetim seçeneklerinin kullanımının sağlanabilmesinin en önemli kriter olduğu tespit edilmiştir. Teknoloji Boyutu ana kriteri incelendiğinde 0,349 ağırlık ile sanal sınıfların oluşturulan derslerde kullanılabilmesinin en önemli kriter olduğu belirlenmiştir. Ölçme ve 
Değerlendirme Boyutu değerlendirildiğinde 0,194 ağırlık ile ödev oluşturma, ödevleri öğrencilere atama ve rubrik ile sistem üzerinden değerlendirmeye olanak tanınmasının en önemli kriter olduğu tespit edilmiştir. Maliyet boyutunda ise 0,315 ağırlık ile yazılım/lisans maliyetinin önemli kriter olduğu AHP analizi sonucunda belirlenmiştir.

\section{Sonuç ve Tartışma}

$\mathrm{Bu}$ çalışmada uzaktan eğitim hizmetleri sunan kurumların ÖYS seçim süreçlerine yönelik bir karar verme yöntem önerisi sunulmuştur. Uzaktan eğitim hizmeti sunan kurumların ÖYS seçim süreçlerinde dikkat etmeleri gereken kriterler, alanyazın ve beraberinde gerçekleştirilen uzaktan eğitim uzmanları ile gerçekleştirilen görüşmeler sonucunda elde edilmiş ve AHP analizi ile de belirtilen kriterlerin ağırlıkları hesaplanmıştır. Bu çalışmada ÖYS seçim sürecinde dikkat edilmesi gereken ana kriterler içerik, iletişim, topluluk oluşturma, teknoloji, ölçme ve değerlendirme ve maliyet olarak tespit edilmiştir.

İçerik boyutu anlamında elde edilen kriterler ve kriter ağırlıkları birçok farklı çalışmada farklı kriterler ile sunulmuştur (Turker, Baynal ve Turker, 2019). Gerçekleştirilen AHP analizi sonucunda İçerik Boyutunda; Evrensel formattaki (pdf, txt, mp3, mp4, png, jpg, swf) malzemelerin derslerde kullanımının sağlanabilmesi kriterinin yüksek ağırlığa sahip olan kriter olduğu tespit edilmiştir. Bu bulgu, alanyazındaki mp4, flv ve diğer dosya formatlarının ÖYS içerisinde uyumunun önemli olduğu diğer çalışmaları destekler niteliktedir (Mekpiroon, Tammarattananont, Pravalpruk ve Buasroung, 2008). Bunun ardından Youtube vb. video paylaşım ortamlarındaki videoların derslerde kullanımının sağlanabilmesinin en yüksek ağırlığa sahip kriter olması alanyazında gerçekleştirilen diğer çalışmaları destekler niteliktedir (Chtouki, Harroud, Khalidi ve Bennani, 2012). Bu bağlamda çalışmada içerik boyutu özelinde en yüksek kriter ağırlığa sahip olan bu ifadelerin video gibi ders malzemelerinin olması dikkat çekicidir. İçerik boyutunda belirlenen kriterlerden diğer yüksek ağırlığa sahip olan kriterler ise öğrenen-içerik etkileşiminin sağlandığı etkileşimli ders malzemelerine ait olanlardır. Çalışmadaki bu bulgularda Anderson'ın (2003) uzaktan eğitim alanına kazandırdığı etkileşim türlerini destekler niteliktedir. İçerik boyutunun son kriteri ÖYS içerisinde bulut depolama ortamlarının entegre edildiği kriterlerdir.

İletişim boyutundaki kriterleri ağırlıklarının hesaplanması sonucunda en yüksek ağırlığa sahip olan kriter tartışma formunun etkili kullanımın sağlanabilmesi olmuştur. Machajewski, Steffen, Fuerte, ve Rivera (2019) tarafından gerçekleştirilen çalışmada e-posta 
ile iletişimin önemli olduğu ifade edilse de bu çalışmada uzmanlar iletişim boyutu bağlamında tartışma forumlarının derslerin içerisinde kullanımının daha önemli olduğunu ifade etmişlerdir. Gelişen teknolojilerin iletişim ortamlarına yansımalarından biri olan mobil teknolojilerinde bu çalışmada önemli bir yere sahip olduğu gözler önüne serilmiştir. Bu bağlamda iletişim boyutunda mobil uygulama içerisinde anında bildirim seçeneklerinin sağlanabilmesi kriterinin yüksek ağırlığa sahip bir diğer kriter olduğu tespit edilmiştir. Hatta mobil uygulamaların ÖYS içerisinde kullanımına dair bu önemli kriter ağırlığı alanyazındaki çalışmalar ile desteklenmektedir (Saw, Win, Aung ve Oo, 2018). İletişim kriterleri bağlamındaki diğer kriterler ise bire-bir veya bire-çok iletişimin uygulandığı kritelerdir.

Topluluk oluşturma boyutunda yer alan kriterlerin analizinde en yüksek ağırlığa sahip olan kriter, dersler içerisinde grup yönetim seçeneklerinin kullanımının sağlanabilmesi olarak tespit edilmiştir. ÖYS içerisinde öğrenciler bir desteğe ihtiyacı olduğunda ilk olarak grup arkadaşları ile iletişime geçmektedir (Steyn, Millard ve Jordaan, 2017). Bu çalışmada da uzaktan eğitim uzmanları grup oluşturulma sürecinin önemli bir kriter olduğunu ifade etmeleriyle ÖYS seçiminde bu kriterlerin önemli olduğu vurgulanmıştır. Bir topluluk oluşturma sürecinde öğrencilerin gruplar halinde organize olabilmelerinin, topluluğun oluşturulması noktasında önemli olduğu kriter ağırlıkları ile gösterilmiştir. Bunların yanı sıra dijital teknolojilerin bir topluluğun oluşturulmasında önemli olduğu görülmektedir. Topluluk oluşturma bağlamı bu açıyla incelendiğinde Microsoft Teams, sosyal medya araçları, Google Hangouts gibi teknolojilerin bir topluluğun oluşturulması amacıyla kullanılmasında önemli olduğu ve kriter olarak değerlendirilmesi gerektiği ortaya çıkmıştır.

Teknoloji boyutunda yer alan kriterler incelendiğinde sanal sınıfların oluşturulan derslerde kullanılabilmesi kriterinin yüksek bir kriter ağırlığına sahip olduğu görülmektedir. Covid-19 pandemisi sonrasında Dünya üzerinde milyonlarca öğrencinin ve öğretmenin bir buluşma noktası olan Zoom veya BigBlueButton gibi teknolojilerin ÖYS içerisinde bulunmasının önemi bir kez daha gözler önüne serilmiştir. Çalışmada farklı elektronik cihazlardan giriş yapılması durumunda duyarlı tasarımın kullanımının, 3.part uygulamalarının ÖYS içerisine entegre edilebilmesinin ve SCORM paketlerinin kullanımının sağlanabilmesinin önemli kriterler olduğu tespit edilmiştir.

Çalışmada sosyal medya araçlarının entegre kullanılabilmesine olanak sağlanmasının bir topluluk oluşturma sürecinde önemli olduğu ve ÖYS içerisinde bulunması gerekliliği ifade edilmiştir. Bu bağlamda çalışmadaki bulgular, sosyal medya araçlarının ÖYS içerisinde 
kullanımı konusunda gerçekleştirilen çalışmaları destekler niteliktedir (Kaewsaiha, 2019). Öte yandan ölçme ve değerlendirme boyutunda, uzaktan eğitim uzmanları tarafından ödev oluşturma, ödevleri öğrencilere atama, ve rubrik ile sistem üzerinden değerlendirmeye olanak tanıması kriterinin önemli olduğu tespit edilmiştir. ÖYS üzerinde de öğrencilerin en çok dikkat ettikleri alanların rubrikler olduğu ifade edilmektedir (Conley, Earnshaw ve McWatters, 2020). Bu bağlamda çalışmadaki bulguların alanyazındaki çalışmalarla destek bulduğu söylenebilir. Steyn, Millard ve Jordaan (2017) tarafından gerçekleştirilen çalışmada basılı ders malzemelerinin yerini kolay ulaşılabilir teknolojilerin aldığg ifade edilmiştir. Çalışmadaki blog araçlarının kullanımı, wiki araçlarının kullanımı ve Youtube videolarının dersler içerisinde kullanımı gibi bulgular, Steyn, Millard ve Jordaan (2017) tarafından gerçekleştirilen çalışmayı destekler niteliktedir.

Maliyet boyutu incelendiğinde yazılım/lisans maliyetinin en yüksek kriter değerine sahip alt kriter olduğu tespit edilmiştir $(0,315)$. Bu noktada uzmanlar açık kaynak kodlu ÖYS'lerde lisans maliyetleri ile karşılaşmıyor iken ücretli araçlarda bu gibi maliyetlerle karşılaşmaktadır. Öte yandan bir diğer önemli kriter ise donanım altyapı maliyeti kriteridir $(\mathrm{w}=0,267)$. ÖYS'lerin alt yapıları kurum içindeki veya kurum dışındaki sunucularda barındırılmaktadır. Kurum içerisindeki öğrenci sayısı, etkileşim araçları ve kullanılan tüm teknolojiler bu gibi donanım alt yapı maliyetlerinde önemli bir konu olarak karşımıza çıkmaktadır. Beraberinde ise danışmanlık hizmetleri, yıllık bakım güncelleme ve genel yönetim maliyetleri yer almaktadır. 


\section{Kaynakça}

Altıparmak, M., Kurt, İ. D. ve Kapıdere, M. (2011). E-öğrenme ve uzaktan eğitimde açık kaynak kodlu öğrenme yönetim sistemleri. XI. Akademik Bilişim Kongresi.

Anderson, T. (2003). Getting the mix right again: an updated and theoretical rationale for interaction. The International Review of Research in Open and Distributed Learning, 4(2). https://doi.org/10.19173/irrodl.v4i2.149

Belton V. (1986). A comparison of the analytic hierarchy process and a simple multi-attribute value function. European Journal of Operational Research, 26, 7-21.

Brandl, K. (2005). Are you ready to "Moodle"? Language Learning and Technology, 9(2), 1623.

Bozkurt, A. (2019). The historical development and adaptation of open universities in Turkish context: case of Anadolu University as a giga university. International Review of Research in Open and Distributed Learning, 20(4), 36-59.

Canvas Guides. (2020). “Improving accessibility to your course”, Erişim: 30 Mayıs 2020 , http://guides.instructure.com/m/5834/1/92747-improving-the-accessibility-of-yourcourse.

Chang, C. C. (2014). Exploring the determinants of e-Learning systems continuance intention in academic libraries, Library Management, 34(1/2), 40-55.

Chen SJ. ve Hwang CL. (1992). Fuzzy multiple attribute decision making: methods and applications. Berlin: Springer-Verlang,

Chtouki, Y., Harroud, H., Khalidi, M., \& Bennani, S. (2012, June). The impact of YouTube videos on the student's learning. In 2012 international conference on information technology based higher education and training (ITHET) (pp. 1-4).

Creswell, J. W. (2007). Qualitative Inquiry and Research Design: Choosing Among Five Approaches. Thousands Oaks, CA: SAGE Publications, Inc.

Creswell, J. W. (2013). Research Design: Qualitative, Quantitative, And Mixed Methods Approaches. New York: Sage. 
Conley, Q., Earnshaw, Y., \& McWatters, G. (2020). Examining course layouts in blackboard: using eye-tracking to evaluate usability in a learning management system. International Journal of Human-Computer Interaction, 36(4), 373-385.

Daniel, J. (1996). Mega-universities and knowledge media: Technology strategies for higher education. London: Psychology Press.

Edutechnica. (2020). "6th Annual LMS Data Update”, Erişim: 30 Mayıs 2020, http://edutechnica.com/2018/10/06/6th-annual-lms-data-update/.

French S. (1988). Decision theory: an introduction to the mathematics of rationality. Chichester: Ellis Horwood,

Hwang CL., Yoon K. (1981). Multiple attribute decision making: Methods and applications: A-State-of-the-Art Survey. Berlin: Springer-Verlag,

Kaewsaiha, P. (2019). Usability of the Learning Management System and Choices of Alternative. In the International Conference on Education, Psychology, and Social Sciences (ICEPS) (pp. 252-259).

Leymun, Ş. O., Odabaşı, F., \& Yurdakul, İ. K. (2017). Eğitim ortamlarında durum çalışmasının önemi. Eğitimde Nitel Araştırmalar Dergisi, 5(3), 367-385.

Liaw, S.S., (2008). Investigating students' perceived satisfaction, behavioral intention, and effectiveness of e-learning: A case study of the Blackboard system. Computers \& education, 51(2), 864-873.

Machajewski, S., Steffen, A., Fuerte, E. R., \& Rivera, E. (2019). Patterns in faculty learning management system use. TechTrends, 63(5), 543-549.

Mekpiroon, O., Tammarattananont, P., Pravalpruk, B. \& Buasroung, N. (2008). Multimedia Courseware with Open Source LMS: Learnsquare. In J. Luca \& E. Weippl (Eds.), Proceedings of ED-MEDIA 2008--World Conference on Educational Multimedia, Hypermedia \& Telecommunications (pp. 197-202).

Merriam, S. B. (2013). Nitel araştırma: Desen ve uygulama için bir rehber (3. Basım). Ankara: Nobel akademik yayıncılık. 
Pendergast, M. (2015). Leveraging Learning Management System to Accommodate Students with Disabilities: Issues and Experiences with the Canvas LMS. In Proceedings of the 18th Southern Association for Information Systems Conference.

Russell JS. (1990). Surety bonding and owner-contractor prequalification: comparison. Journal of Professional Issues in Engineering. 116(4), 360-74.

Saaty, T. L. (1977). A scaling method for priorities in hierarchical structures. Journal of Mathematical Psychology, 15(3), 234-281.

Saaty TL. (1989). Group decision making and the AHP. New York: Springer Verlag,

Saw, T., Win, K. K., Aung, Z. M. M., \& Oo, M. S. (2018, May). Investigation of the Use of Learning Management System (Moodle) in University of Computer Studies, Mandalay. In International Conference on Big Data Analysis and Deep Learning Applications (pp. 160-168).

Schuyler JR. (1996). Decision analysis in projects. Upper Darby, PA, USA: Project Management Institute,

Stake, R.E. (1995). The art of case study research. Thousand Oaks: Sage Pbc.

Steyn, R., Millard, S., \& Jordaan, J. (2017, September). The use of a learning management system to facilitate student-driven content design: an experiment. In International Symposium on Emerging Technologies for Education (pp. 75-94).

Tawalbeh, T. I. (2018). EFL Instructors' perceptions of blackboard learning management system (lms) at university level. English Language Teaching, 11(1), 1-9.

Turker, Y. A., Baynal, K., \& Turker, T. (2019). The evaluation of learning management systems by using Fuzzy AHP, fuzzy topsis and an integrated method: A case study. Turkish Online Journal of Distance Education, 20(2), 195-218.

Vassilev V, Genova K ve Vassileva M (2005). A brief survey of multicriteria decision making methods. Bulgarian Academy of Sciences Cybernetics and Information Technologies. $5(1), 4$.

Von Winterfeldt D., Edwards W. (1986). Decision analysis and behavioral research. Cambridge: Cambridge University Press,

Yacan, İ. (2016). Eğitim kalitesinin belirlenmesinde etkili olan faktörlerin bulanık AHP ve Bulanık Topsıs yöntemi ile değerlendirilmesi (Yayımlanmamış yüksek lisans tezi). 
Pamukkale Üniversitesi, Denizli.

Yin, R.K. (2014). Case study methods: design and methods (5. Baskı). Thousand Oaksage Pbc.: S.

Zeleny M. (1982). Multiple criteria decision making. NewYork: McGraw-Hill. 


\section{Yazarlar Hakkında}

\section{Öğr. Gör. Murat ARTSIN}

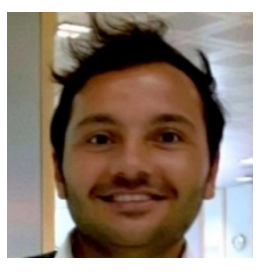

Murat Artsın, Bilecik Şeyh Edebali Üniversitesi Açık ve Uzaktan Öğrenme Uygulama ve Araştırma Merkezinde görev yapmaktadır. Artsın, lisans eğitimini Sakarya Üniversitesi Bilgisayar ve Öğretim Teknolojileri Eğitimi Bölümünde 2016 yılında tamamlamıştır. Yüksek lisans eğitimini ise Anadolu Üniversitesi Uzaktan Eğitim Bölümünde 2018 yllında tamamlamıştır. Artsın, Bahçeşehir Üniversitesi Eğitim Teknolojileri Bölümünde Doktora eğitimine devam etmektedir. Yazar yükseköğretimde uzaktan eğitim ders tasarımı, materyal geliştirme ve alt yapı hizmetleri konusunda tecrübeye sahip olup uzaktan eğitim ve eğitim teknolojileri ile ilgilenmektedir.

Posta adresi: $\quad$ Bilecik Şeyh Edebali Üniversitesi Rektörlüğü Bilgi İşlem Daire Başkanlığ Gülümbe Kampüsü Tel (İş): 11230-BİLECIK

Eposta: $\quad$ artsinm@gmail.com

URL:

https://bilecikedu.academia.edu/MuratArts $\% \mathrm{C} 4 \% \mathrm{~B} 1 \mathrm{n}$

URL:

URL: https://www.researchgate.net/profile/Murat_Artsin https://www.linkedin.com/in/muratartsin/

URL: http://pvs.bilecik.edu.tr/murat.artsin/

\section{Kaan GÜNAL}

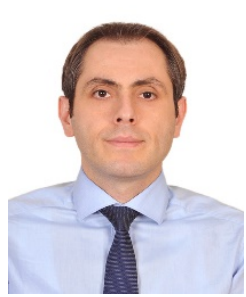

Kaan Günal, EPİAŞ’de Kurumsal Mimari Müdürlüğü personeli olarak görev yapmaktadır. Günal, lisans eğitimini Dumlupınar Üniversitesi, Matematik bölümünde 2005 yılında tamamlamıştır. 2015 yılında Bahçeşehir Üniversitesi Mühendislik Yönetimi yüksek lisans bölümünden mezun olmuştur. Günal, Bahçeşehir Üniversitesi İşletme Mühendisliği Doktora programına halen devam etmektedir. Yazarın ilgi alanları, finansal piyasalar, yönetişim, stratejik planlama, proje yönetimidir.

Posta adresi: Bahçeşehir Üniversitesi Güney Kampüsü Beşiktaş/İstanbul E-posta: kaangunal@gmail.com URL: https://tr.linkedin.com/in/kaangunal

URL: https://www.researchgate.net/profile/Kaan-Gunal 